\title{
Simulation Games in the Project Management Environment
}

\author{
Juan L. Cano, Ruben Rebollar, Maria J. Sáenz \\ Project Engineering Area. Faculty of Engineering. University of Zaragoza
}

E-mail:jlcano@posta.unizar.es,rebollar@posta.unizar.es,mjsaenz@posta.unizar.es

Key words: simulation games, project management, negociation, training tool, roleplaying.

Abstract: The paper describes and analyses the experiences obtained in the development of PROSIGA and TRAINER games in the project management environment. The benefits of using simulation games are presented, as well as the outlooks for further work with this type of tools. Different aspects of the games development process are commented and specifically the overall effort involved is exposed.

\section{NEED}

The increasing introduction of project management philosophy in industry, clearly shown by the tremendous increase in the number of official members of the PMI (Project Management Institute), IPMA (International Project Management Association) and AIPM (Australian Institute of Project Management), is a good indicator of the growing training demand in this field. It is necessary to provide ways to experiment in which it is possible to act out the management of a project.

In order to learn how to manage a project, the best method is to manage it. For that reason, a series of tools has been developed that, by means of 
simulation, reflect the different aspects to be treated throughout the management of a project: negotiation, dealing with conflicts, project planning and controlling, decision making, group working, etc.

Simulation techniques are used in a wide range of fields, from mechanical engineering to risk management or re-engineering, in order to test without paying the costs of mistakes (Haho, 1996; Riis, 1996; Cano 1, 1994). In the learning process, these techniques give us the opportunity to deal with "virtual" situations which bear resemblance to those we try to solve in real life.

The basic purpose of this paper is to comment on some aspects and features of the development of simulation games specifically for the project management environment.

\section{BACKGROUND}

According to the main aim of project management training, we have participated in the following European programmes: SAM (Simulation Aided Management) and SAM-Mobil, within the framework of the COMMET Programme, and CAESAR (Computer Aided Education with a Simulation Approach for the Redesign of Production Processes) within the LEONARDO DA VINCI Programme. These projects have resulted from the collaboration between different European universities: Karlsruhe, Gent, and Zaragoza, in all the cases and with Dortmund and Lyngby in the case of the first two projects. Our work consist of developing training modules for project management, as part of a overall seminar in which each University was in charge of a training module related to a common scenario referring to a bike manufacturing company. Our project management seminar is based on the project simulation games PROSIGA and TRAINER, which are presented in the following sections.

Currently these tools are successfully used in many courses for industry focused on the retraining of engineers and for university post-graduate programmes.

\section{SIMULATION GAMES DEVELOPED}

The simulation games developed have been PROSIGA (PROject SImulation GAme) and TRAINER (TRAIning for NEgotiation through Role-playing). Both simulation games provide learning and training experiences on how to develop team working, decision-making, communication and project management skills. 
In the training seminars, the participant takes part in the different phases of the whole life cycle of a project, through PROSIGA and TRAINER. According to a common scenario, the participants experience the management of a project from the first need which motivates the execution of the project, to the starting of the new bicycle manufacturing company, as is indicated in Figure 1. The progress of the project over the elapsed time, with the main phases of PROSIGA and TRAINER is shown.

Both games cover the whole project life cycle. PROSIGA shows the project life paces under a simulated "continuous" pattern. TRAINER covers three specific situations around a supply contract that occur at three different moments of the project development.

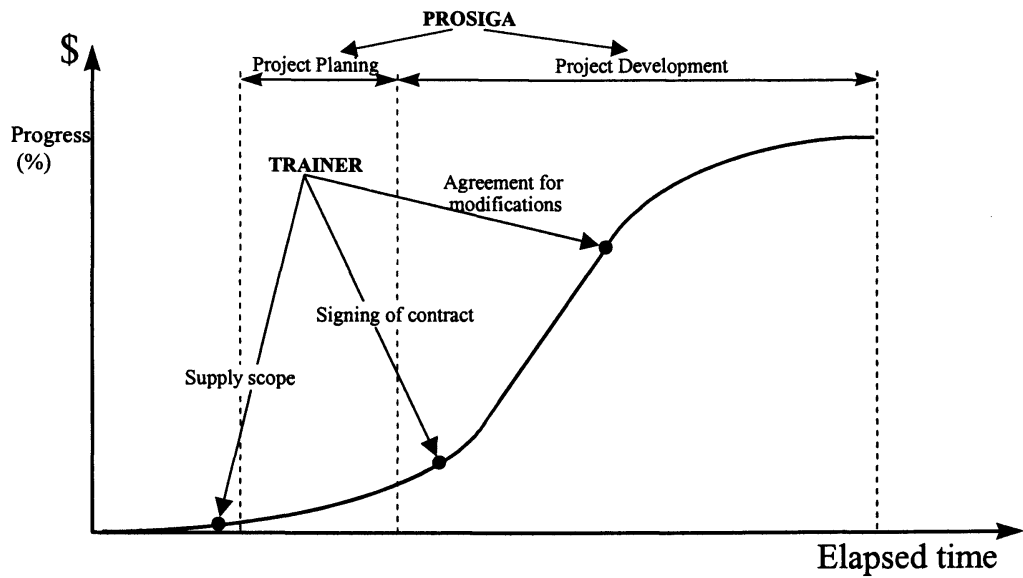

Figure 1. Simulation games through the project life cycle.

In PROSIGA, the participants act as the project manager who must make strategic and operational decision to achieve overall objectives (see Figure 2). The example which is proposed by the simulator, is a project to set up a new bicycle plant in a country bordering the European Union (EU) supported by a EU technology transfer programme. With this story line, the participants in groups, assume the role of project managers who have to make decisions in order to achieve the targets required by the company board of directors. From the beginning, they are under time pressure trying to solve conflicts. The decisions made, influence the project development in different ways (costs, delay, team motivation, management support, etc.). By means of simulation we create an interactive, real environment where management skills can be trained without the risk of failure (Cano 2, 1998). The participants have to manage two phases through PROSIGA (see Figure 1): 
- $\quad$ PROSIGA I. Project Planning: the participants collaborate in the preparation of a proposal, handling the concepts of project scheduling, and practising through the successive levels, preparing an initial draft of the master plan, and later adjusting it to time limits, weighing up the different alternatives available.

-

PROSIGA II. Project Development: a series of situations will be experienced. These situations occur during the development of the project up to the commissioning and final reception of the plant. Therefore, the participants should take a series of decisions which will be required as the project progresses. Moreover, they are able to observe the results these decisions have on the project.

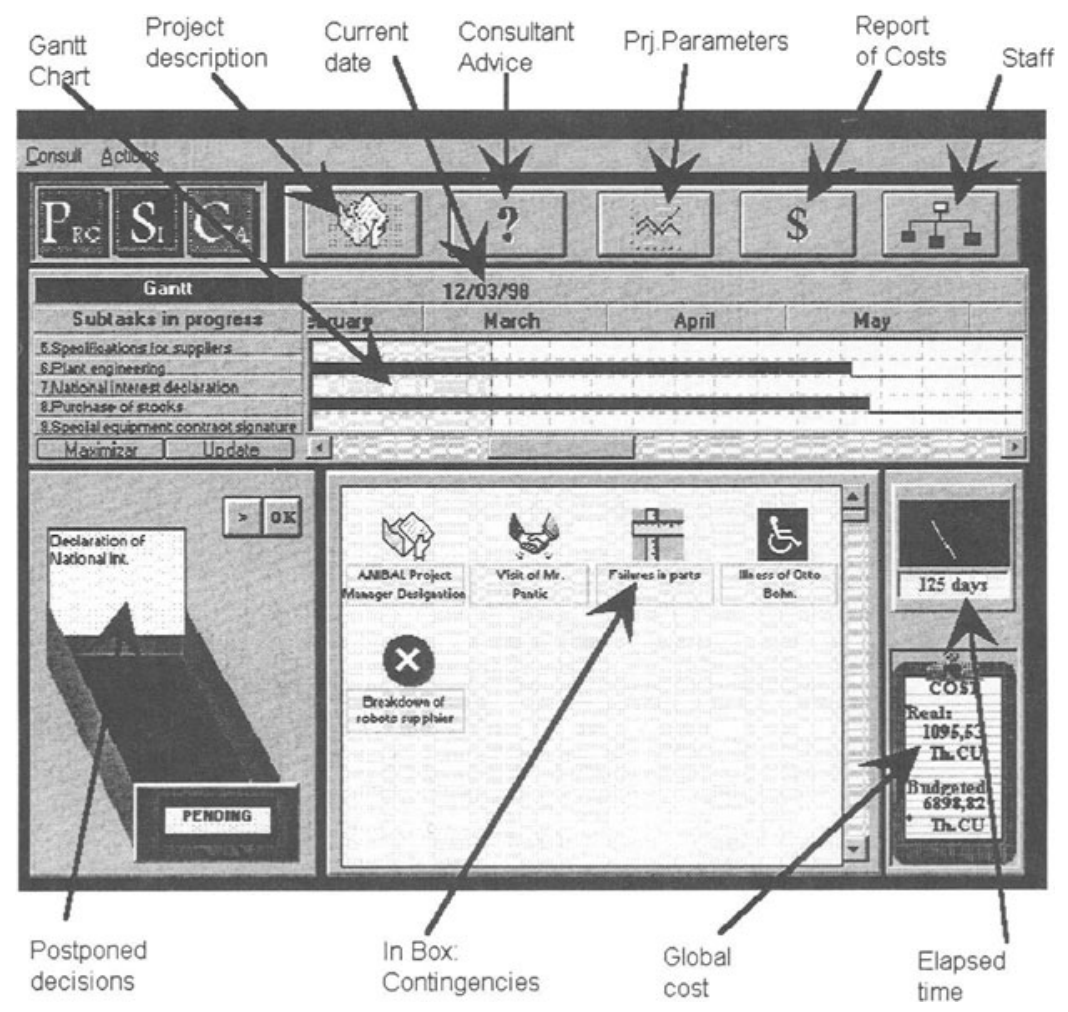

Figure 2. Project manager desk in PROSIGA.

TRAINER is a simulation game devoted to training negotiation skills. In an appropriate scenario around the supply of plastic injection moulds, the participants act as members of three companies, assuming the roles of 
customer, engineering company and mould manufacturing workshop (Cano 3, 1998) (see Figure 3). Through the simulation game TRAINER, they have to pass through the different phases in a contract negotiation (see Figure 1):

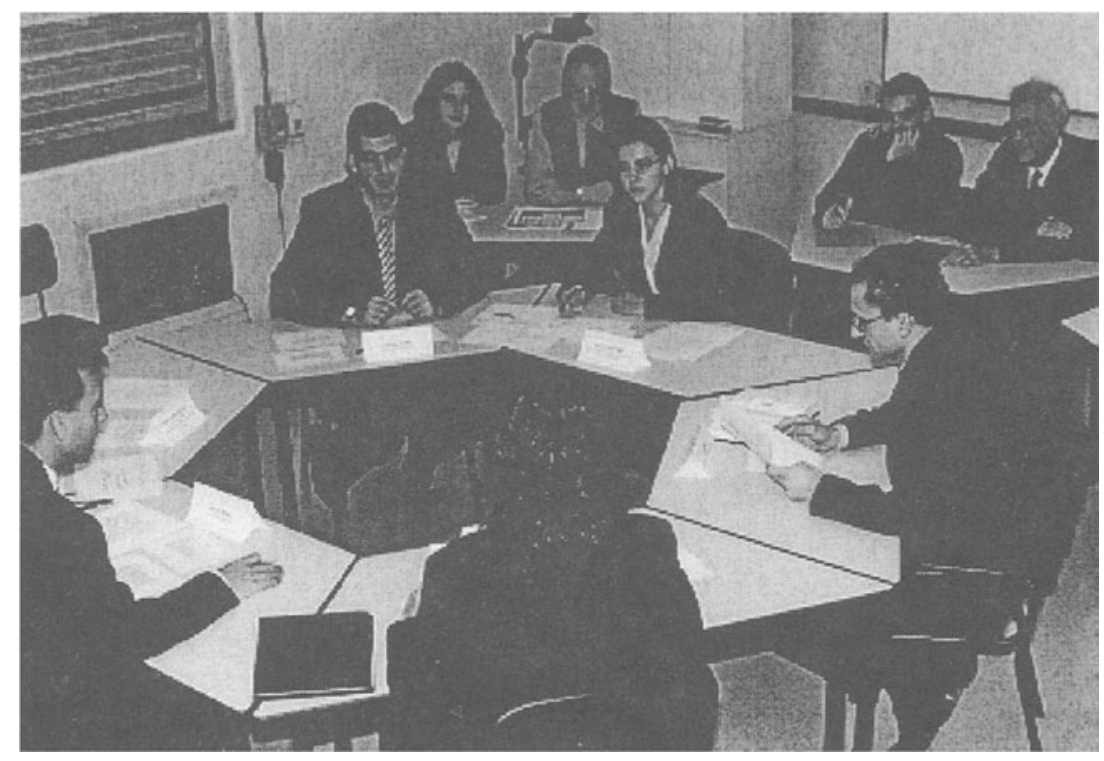

Figure 3. Performance at TRAINER seminar.

TRAINER I. Supply scope and Signing Contract: the participants begin to get to know the scenario in which the companies have to act, essentially they become aware of the negotiation goal. Once they are familiar with the situation, they have to participate in a simulation of a meeting where a contract between three companies is negotiated, the ultimate aim being to sign an agreement. The parameters to negotiate refer to aspects such as supply terms, costs, penalties for delays in the supply and future commitments.

TRAINER II. Agreement for modifications: the companies involved in the negotiation have already signed a contract, it work has begun on the project and a modification suggested by the customer arises. The simulation of the negotiation will be based on the use of an information system as a way of measuring the impact of the modification asked by the companies, so with the data obtained the agreement is negotiated again. In this second module, the parameters which are negotiated are based on the information system, such as costs, resources, terms, etc. 


\section{ASPECTS TO BE CONSIDERED IN THE GAMES DEVELOPED}

According to the experience obtained during the games development process in which we have been involved, some aspects appear to be particularly relevant, such as: the scenario development, versatility of the scenario, interactivity, group work, game timing, results evaluation, general development process, usability of the game interface, test scheduling, expert seminars and overall effort.

\section{a) SCENARIO DEVELOPMENT}

It is necessary for participants to be encouraged to relate their own and their companies experiences to the particular situation in which the game is simulated. On the other hand, the scenario has to allow us to locate the participant in such a way that he/she assumes the role required. The task of development of the scenario, as such, is similar to the work of a writer when producing a film script. In the sense that it is essential to perfectly define the framework situation with the right sequence of scenes in which the action is going to be performed, the characters, with their abilities and limitations, and the tasks to be accomplished during the project development (Kirby, 1992). In the project simulation game scenario, different situations, conflicts and anecdotes arise. The participants have to deal with them making the right decisions at the right time.

The script content requires the retrieval of prior real experiences in industry. The story has to hold the interest of the participants and, at the same time, be considered as realistic by them.

\section{b) VERSATILITY OF THE SCENARIO}

Some transformations can be carried out in a short time achieving a simple variety of scenarios, which widens the game's adaptability to different environments. In this case, it would be necessary to implement a type of "macro-language" open to a limited variety of scenarios and situations.

\section{c) INTERACTIVITY}

The game's rules of decision / response require a certain degree of agility we should not wait for the game to react. The rhythm of the project (typical decision making process under the pressure of time) has to be present at a reduced scale during each phase of the game. In addition, the game provides help and information about the project, so that participants manage, in their particular group, to interact with the tool and extract as much knowledge as possible from the experience. On one hand we have to control the game pace in the sense that the flow of conflicts/situations should not to overwhelm the participants, which would not allow each of them to be treated in a suitable 
manner. On the other hand if the flow is rather low the participants have to wait for the system, which means loss of attention and boredom in the end. Another point to pay attention to is the interaction between the instructor and the participant because a compromise between the help the participants need and the degree of freedom of performance in the simulation has to be achieved.

\section{d) GROUP WORK}

These games have to adapt to a relationship in which the participant learns more from his/her partners than from the conductor of the seminar (Gardner, 1995). The main interest of the seminar is based on the trade-off situations which can be tackled from different perspectives by each group. Generally this type of seminar could use different techniques so that different skills could be practised in diverse contexts. For instance, we are interested in dealing, in groups, with the dissimilar decisions which may be made with regard to the project progress but, on the other hand, we may want the same people to enter into a discussion each one performing a different role, for example, to negotiate the terms of the equipment commissioning. In the first case we may use a simulation game such as PROSIGA (Project Development phase) and in the second one, games based on the role-playing techniques such as TRAINER.

\section{e) GAME TIMING}

The time sequence of the training seminar directly affects the structure of the game. Each part of the game and its duration will be delimited depending on the evolution of the seminar. A typical time distribution of the seminar would comprise $1 / 3$ for the setting up of the seminar where the participants have to learn some theory about the seminar topics and the scenario itself, $1 / 3$ for the practical aspect where the players experiment with the topics learned in the previous knowledge phase, and $1 / 3$ for the debriefing session where the game evaluation and results presentation take place.

\section{f) RESULTS EVALUATION}

In all the simulation games, the participants expect to receive the feedback of the evaluation of the sequence of their decisions, from the point of view of the expert who knows the right solution to the problems tackled. With this evaluation a competitiveness effect is also obtained, which forces the participants to make an extra effort in order to obtain better results. This effect also serves to learn from their own mistakes and from the mistakes made by the rest of the participants (Elgood, 1993).

\section{g) GENERAL DEVELOPMENT PROCESS}

In order to be able to improve the development process of a simulation game 
it is necessary to integrate the efforts of the developers, the trainers and the observers (see Figure 4). The seminar trainers contribute to the improvement process with their opinion about how the game can be improved to assure its pedagogical value. The observers help to detect which aspects of the game can be improved, in view at how the participants interact with it. It can be seen that the game developers do not perceive all its peculiarities that the participants discover through the use of the game. The task of subsequent analysis of each one of the seminars must be added to the effort of integration, since the enormous amount of data gathered has to be adapted in order to find the more relevant aspects that lead to the improvement of the game. For the game to survive, the work spiral should not be stopped and it is necessary to assure that all the process development areas (design, observation and training) contribute to this progress.

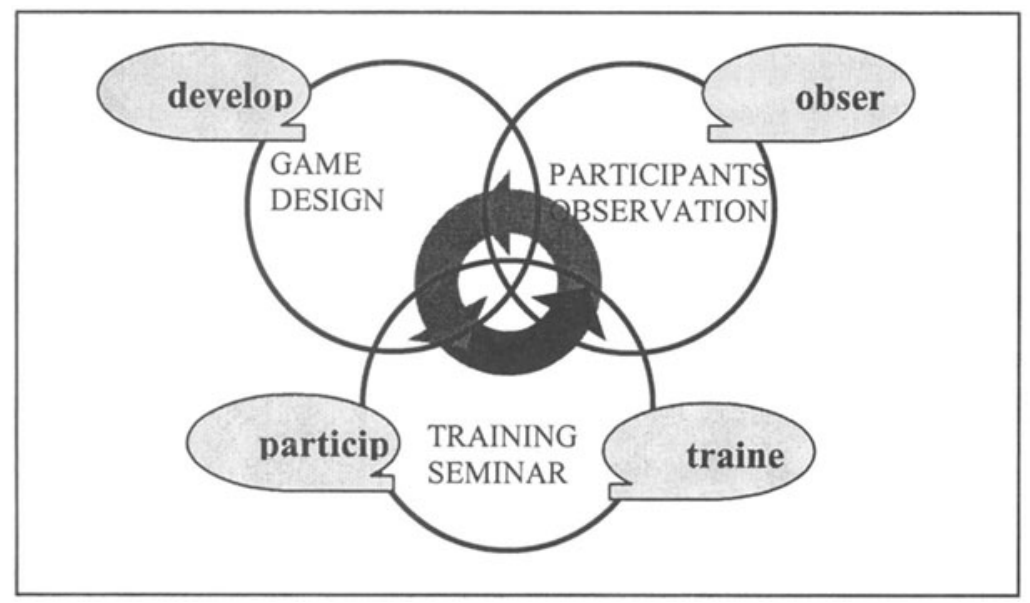

Figure 4. General development process.

\section{h) USABILITY}

A very representative example of the "general development process", presented in the last topic, is the usability improvement process. In the case of PROSIGA which is a computer based game, we need to see how other people interact with the simulator in order to detect the points that require improvement. The interface design, the information shown on the screens, the menus, the error messages, the application help, etc. have been progressively modified through different tests in order to achieve a higher degree of usability in the game (Dumas, 1994; Nielsen, 1994). Due to the fact that analysts/developers are unable to appreciate in advance the type of difficulties that the users will have to work out by interacting with the game, an independent group had to be created. This group was devoted to 
monitoring the usability tests of the successive PROSIGA versions following the process showed in Figure 5. This group of observers has had to interact with the game developers and the seminar trainers to discuss all together which ideas would be feasible to implement in order to solve the interface problems detected, and to deal with the training needs of the whole seminar (Cano 4, 1998).

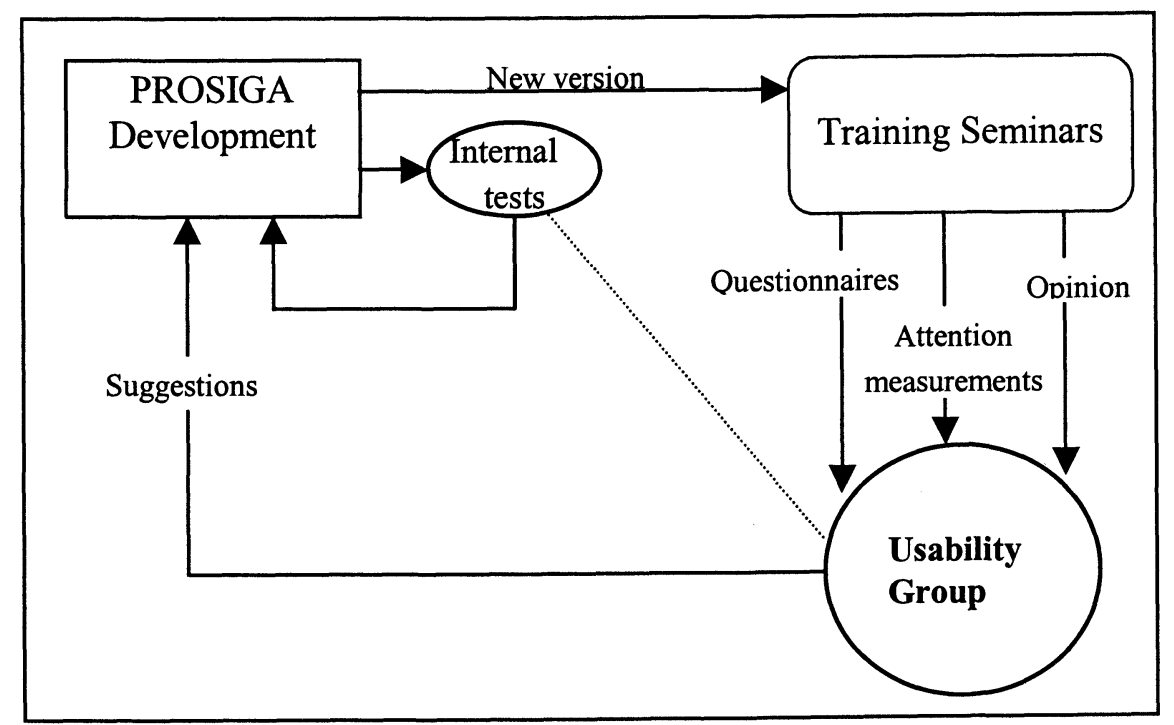

Figure 5. Usability improvement process.

The usability group has obtained information from four main sources:

- Direct observations of the players using the game, for which a data capturing template has been used in order to standardise this procedure. This is, without any doubt, the most laborious task, since each observer must be placed behind a group of players, for three hours, the duration of a typical simulation session. The observers have to jot down all the data that could be of interest in order to discover usability problems such as mistakes made, incorrect behaviour, players exclamations, sequences of activities, importance they give to certain information, etc.

- Use of scan-converter. It is a device that allows the recording on video of all the actions that the player carries out with a computer. This device has been employed in the final phase of the project and at the same time as the direct observation of the rest of the seminar groups. 
- Opinions expressed by the trainers in charge of giving the seminar.

- Participants' questionnaires with their opinion about the application.

Once the information has been gathered after each seminar, a debriefing by all the members of the usability group is carried out. A series of conclusions are deduced and they are transformed into a list of suggestions to implement in the game and in the seminar as well.

As can be observed in Figure 5 this is an iterative process, and for this reason the new "version" of the application is tested in the following seminar and then all the improvement process is repeated.

\section{i) TEST SCHEDULING}

Due to the "general development process", we need to see how others play with the simulation to become aware of the points in need of improvement. For that reason, planning test seminars sufficient time in advance is a must for the game's design, because the efforts of many people have to be integrated: observers, developers, trainers and new players all of whom are required to attend each test-course. In this way we detect how to act in relation to, for example, the duration of the game phases, time that the player needs to think out the strategy, difficulties handling the information available, the way in which the trainer musts interact with the participants, etc.

\section{j) EXPERT SEMINARS}

Experts (practitioners and University teachers) have been filmed, participating in the sessions with the simulation games. The result has been very positive since very clear examples of how to focus the situations and how to handle the diverse techniques are obtained. This material is extremely valuable to identify, in the classroom, aspects to be reinforced, and the strategies that are employed by the participants.

k) EFFORT

The development of these simulation games has involved a huge effort that can be summarised in ten years/man, since May 96 until June 98 . This effort includes tasks such as: game specifications, analysis and design, application implementation, internal tests and formal seminars to students, postgraduates and practitioners. 


\section{CONCLUSIONS}

The use of the project management simulation games, PROSIGA and TRAINER, has been a very positive experience. From the teacher point of view, they become a basic requirement in the teaching of project management practice and the beneficial added value that the to integration of these tools in project management training supposes, is shown. Moreover it has been demonstrated that project management simulation game development is a extremely work consuming activity.

As a result of the work of three years, a series of aspects has been emphasised in the development of this kind of tools. It is worth while remarking that a specific means of development based on an integrated process between developers, observers and trainers has been implemented. Due to this effort, simulation games evolve thanks to an on-going process of improvement. This process has obtained very positive results given that problems, that the development games group would not have been able to discover by themselves, have been detected.

We are going to continue experimenting with the tools and the seminars and we expect to keep on learning and researching on how to extract the best knowledge from the simulation games in the field of project management. Finally we are strongly in favour of continuing to work on research into the project management practitioners' behaviour through this kind of simulation games.

\section{REFERENCES}

Cano J.L. (1994) Juego de Simulación de Proyectos. I Congreso Internacional de Ingenieria de Proyectos. Oviedo.

Cano J.L., Sáenz M.J. and Sanz D. (1998) Development of a Project Simulation Game. $14^{\text {th }}$ World Congress on Project Management. Slovenia.

Cano J.L., Cebollada J., Mariscal A. and Sáenz M.J. (1998) Development of a Negotiation Simulation Game in the Project Management Environment. IV International Congress of Project Engineering. Cordoba.

Cano J.L., Rebollar R. and Sáenz M.J. (1998) Application of Usability Techniques to the Development of a Project Simulation Game. IV International Congress of Project Engineering. Cordoba.

Dumas, J.S. and Redish J.C. (1994) A practical guide to usability testing. Ablex publishing corporation. New Jersey.

Elgood, C. (1993) Handbook of Management Games. Gower Press. England.

Gardner R. (1995) Games for Business and Economics. Ed. John Wisley \& Sons, Inc.

Haho P. and Smeds R. (1996) Benefits from using simulation Games in Business Process Development. Proceedings of $6^{\text {Th }}$ IFIP - APMS'96. Kyoto.

Kirby, A. (1992) Games for trainers. Volume 1. Ed. Gower. Cambridge.

Nielsen, J. (1994) Usability Engineering. AP Professional. New York. 
Nielsen, J. and Mack, R.L. (1994) Usability Inspection methods. Wiley \& sons. New York.

Riis J.O., Smeds R., Johansen J. and Mikkelsen H. (1996) Games for Organizational Learning in Production Management. Proceeding of $6^{\text {Th }}$ IFIP - APMS'96. Kyoto.

\section{BIOGRAPHY}

\section{Juan L. Cano}

$\mathrm{He}$ is a full professor in the Dept. of Design \& Manufacturing Engineering at the University of Zaragoza (Spain). He gained the $\mathrm{MsC}$ on Mechanical Engineering and his $\mathrm{PhD}$ in Mechanical Design at the Technical University of Madrid (ETSIIM). He worked for fifteen years in industry as Mech. Engineer management consultant, salesman, and project manager, before getting a chair at the University of Zaragoza. He is involved in teaching, consultancy and research in product engineering and project management. He is the president of AEIPRO (Spanish Project Engineering Association).

\section{Rubén Rebollar}

$\mathrm{He}$ obtained the $\mathrm{MsC}$ on Electrical Industrial Engineering at the University of Zaragoza and now is working in this University teaching ergonomics and project management. The focus of his research work is design process and usability.

\section{María J. Sáenz}

She is involved in teaching project management in the Industrial Engineering Master at the Faculty of Engineering, at the University of Zaragoza, where she obtained the MsC on Electrical Industrial Engineering. She has participated in European projects on project management simulation games and she also continues researching in this field in the Dept. of Design \& Manufacturing Engineering. She is the coordinator of AEIPRO-Joven (Young branch of AEIPRO, Spanish Project Engineering Association). 